\title{
FATORES QUE FAZEM DE UMA TRADUÇÃO A TRADUÇÃO \\ FATTORI CHE FANNO DI UNA TRADUZIONE LA TRADUZIONE
}

Maria Franca Zuccarello (UERJ) ${ }^{1}$

Chamou-se-lhe, por isso, o nome de Babel, porque ali confundiu o Senhor a linguagem de toda a Terra, e dali os dispersou por toda a superficie dela

(Gênesis, 11, 9)

\section{Resumo}

Com este nosso trabalho objetivamos refletir sobre estudos que vêm sendo realizados referentes a respeito da formação de uma teoria que servisse para todos os tipos de tradução, relembrando, mesmo que de forma concisa, alguns dos mais conceituados teóricos de vários e diversos países que se pronunciaram a respeito da tradução e cuja variedade e riqueza de pesquisas se referem ao ato tradutório. Tais estudos, seja no que se refere ao seu aspecto de gênero textual, seja quanto à abordagem teórica, no decorrer do tempo seguiram diferentes correntes e nos demonstraram as dificuldades, mesmo quando não são tão latentes, de declarar que exista uma disciplina que ensine verdadeiras regras: o importante é conhecer a língua e a cultura do país de partida e a do país de chegada, que, sem dúvidas alguma, são de primordial importância para solucionar os casos que ocorrem no decorrer do oficio do tradutor.

Palavras-chave: Reflexão, estudos de tradução, teóricos da tradução, tradutor

\footnotetext{
${ }^{1}$ Professora de Italiano da UERJ; Doutora em Língua e Literatura Italiana pela UFRJ
} 


\section{Riassunto}

$\mathcal{L}$ 'obiettivo di questo nostro lavoro è quello di riflettere a rispetto degli studi che già da tempo si fanno e che riguardano la formazione di una teoria che serva a tutti i tipi di traduzione, ricordando qui, anche se in maniera concisa, alcuni dei piú concettuati teorici di vari e diversi paesi che hanno scritto a questo rispetto, e la cui varietà e ricchezza di ricerche si riferisce all'atto traduttivo. Tali studi, sia per quanto riguarda il loro aspetto di genere testuale, sia per il loro approccio teorico, nel decorrere del tempo, hanno seguito differenti correnti e ci dimostrano la difficoltà, anche quando non sono così latenti, di dichiarare che esistano vere regole di traduzione di cui ci si possa servire, malgrado se ne stia parlando molto. Affinché si ottenga una buona traduzione ciò che è veramente necessario è sapere la lingua e la cultura del paese di cui si sta traducendo e quella in cui si traduce, che sono senz'altro di primordiale importanza per la soluzione dei casi in cui ci s'imbatte nel decorrere dell'ufficio del traduttore.

Parole chiave: Riflessioni; studi di traduzione; teorici della traduzione; traduttore.

Iniciaremos reportando-nos às palavras do escritor italiano e teórico de semiótica e tradução, Umberto Eco, o qual diz que quando ainda não existiam teorias da tradução, isto é, desde São Jerônimo até o início do séc. XX, as únicas observações interessantes sobre o ato tradutório vinham dos próprios tradutores, mesmo que, às vezes, eles tivessem um limitadíssimo conhecimento de línguas estrangeiras, como é o caso de Santo Agostinho. 


\section{Em seu ensaio Riflessioni teoriche pratiche sulla traduzione ${ }^{2}$, Eco afirma que}

para fazer observações teóricas sobre o ato tradutório seria muito útil ter tido experiência ativa ou passiva de tradução.

Mi chiedo se, per elaborare una teoria della traduzione, sia parimenti necessario non solo esaminare molti esempi di traduzione, ma aver fatto anche una di queste due esperienze: o aver tradotto o esser stato tradotto - o, meglio ancora, esser stato tradotto collaborando col proprrio traduttore. ${ }^{3}$

E termina sua reflexão dizendo:

In conclusione, una teoria della traduzione deve tener conto di una serie di elementi che, se non sono linguistici, sono però semiotici, in senso lato, nella misura in cui una semiotica tiene conto dell'enciclopedia generale di un'epoca e di un autore, quale viene postulata da un testo, come criterio per la sua comprensione. ${ }^{4}$

Segundo Eco, um autor que segue os próprios tradutores parte de uma exigência implícita de fedeltà, mesmo que este termo possa parecer em desuso diante de propostas críticas pelas quais em uma tradução conta somente o resultado que se realiza no texto e na língua de chegada:

[...] Tradurre fedelemente significa rendere il testo comprensibile a un lettore di lingua diversa, ed è in questa tensione che si articola il problema della "fedeltà", che è sempre fedeltà-per-qualcuno, ovvero fedeltà di qualcuno rispetto a qualcosa d'altro al servizio di qualcun altro ancora. Nel corso delle mie esperienze di autore tradotto ero continuamente combattuto tra il bisogno che la versione fosse fedele a quanto avevo scritto e la scoperta eccitante di come il mio testo potesse (o forse dovesse) trasformarsi nel momento in cui veniva ridetto in altra lingua. E se talora avvertivo delle impossibilità - che pure andavano in qualche modo risolte - più spesso ancora avvertivo delle possibilità: vale a dire che avvertivo come, al contatto con l'altra lingua, il testo esibisse potenzialità interpretative che erano rimaste ignote a me stesso, e come talora la traduzione potesse migliorarlo (dico "migliorare" proprio rispetto all'intenzione che il testo stesso veniva improvvisamente

2 ECO, Umberto. Riflessioni teorico-Pratiche sulla traduæione in Teorie Contemporanee della traduzione, a cura di Siri NERGRAARD. Milano: Bompiani, 1995, p. 121-146.

3 Idem, p. 121. "Pergunto-me se, para elaborar uma teoria da tradução seja necessário não somente examinar muitos exemplos de tradução, mas também ter tido uma destas duas experiências: ter traduzido ou ter sido traduzido - ou, melhor ainda, ter sido traduzido colaborando com o próprio tradutor".

${ }^{4}$ Idem, p. 124. "Concluindo, uma teoria da tradução deve levar em conta uma serie de elementos que, se não forem linguísticos, são semióticos em senso lato, na medida em que uma semiótica observa a enciclopédia geral de uma época e de um autor, postulado por um texto, como critério para a sua compreensão". 
manifestando, indipendentemente dalla mia intenzione originaria di autore empirico)..$^{5}$

Para concluir o seu conceito de fidelidade, diz que este tem relação com o fato de que a tradução é uma forma de interpretação a qual, ao ser "escrita" pelo tradutor, deve sempre mirar - partindo da sensibilidade e da cultura do leitor - a reencontrar, não a intenção do autor, mas a intenção do texto, isto é, aquilo que o texto diz ou sugere ao leitor quanto à língua na qual é escrito e ao contexto cultural no qual é nato, porque uma tradução nunca é somente um problema linguístico, e não o seria até se existisse um critério absoluto de sinonímia.

Eco, como exemplo elementar, toma a forma inglesa "It's raining cats and dogs", que em italiano não pode ser traduzido ipsis litteris, isto é, "Piove cani e gatti", pois a frase usada para se dizer que chove muito é "Piove a catinelle", ou "Piove come Dio la manda". Transportamos, então, a mesma expressão para o português e vimos que também não a traduziríamos com "Chove cães e gatos", e sim com "Chove a cântaros", apesar desta expressão brasileira ter caído em desuso, preferindo-se dizer "Chove pra caramba", ou "Chove muito". Vimos que na tradução da frase inglesa, em nenhuma das duas línguas foi mantida a "fidelidade linguística", embora se tenha mantido a fidelidade cultural.

Para Umberto Eco, o paradoxal é que, mesmo não havendo regras para estabelecer de que forma e por quais motivos uma tradução deve ser fiel, é necessário que, ao julgá-la, prevaleça a metarregra pela qual uma tradução deve ser fiel. Os critérios de fidelidade podem até mudar, mas devem ser

\footnotetext{
${ }^{5}$ Idem, p. 122. "Traduzir fielmente significa tornar o texto compreensível para um leitor de outra língua, e é nesta tensão que se articula o problema da "fidelidade", que é sempre fidelidade para alguém, isto é, fidelidade para alguém com referência a alguma coisa de diferente ao serviço de algum outro mais. No decorrer de minhas experiências de autor traduzido lutava continuamente entre a necessidade de que a versão fosse fiel ao que eu havia escrito e a descoberta excitante de como o meu texto pudesse (o talvez devesse) se transformar no momento em que era reescrito em outra língua. E se, às vezes, eu percebia algumas impossibilidades - que de qualquer forma deviam ser resolvidas - mais frequentemente percebia como, ao contato com outra língua, o texto exibia potencialidades interpretativas que tinham ficado despercebidas a mim mesmo, e como talvez a tradução pudesse melhorá-lo (digo "melhorar" exatamente como era intenção que o próprio texto vinha repentinamente manifestando, independentemente de minha intenção originaria de autor empírico)".
} 
contratados dentro da cultura e devem manter-se coerentes no âmbito do texto traduzido.

Eco diz ainda que uma tradução, para ser satisfatória, deve manter o sentido do texto original ou, eventualmente, ampliá-lo, sem, porém, contradizê-lo. Mas, para que isso aconteça, é preciso lembrar, mais uma vez, que traduzir significa interpretar e que interpretar quer dizer apostar que o sentido por nós reconhecido em um texto, sem que haja evidentes contradições co-textuais, seja o sentido daquele texto. E o sentido que o tradutor deve encontrar e traduzir é o resultado de sua interpretação.

Para exemplificarmos as palavras de Eco, gostaríamos de falar a respeito da dificuldade que qualquer tradutor tem ao traduzir o autor italiano Primo Levi: o tradutor deve ter em seu repertório vários sinônimos que signifiquem quase a mesma coisa, pois como ele mesmo diz em suas obras, era um químico que ao relatar sua vida no Lager torna-se escritor, conservando, porém, a exatidão de um químico que pesa e repesa suas palavras para que estas possam conter toda a exatidão que o autor quis thes dar e que, muitas vezes, não encontram correspondência em português.

Isso nos é demonstrado na poesia Shemá, epígrafe do livro que o consagrou escritor, um de seus textos mais difíceis de serem traduzidos e para o qual há várias versões.

Exemplificamos nossas palavras acima colocando a nossa tradução, e uma outra com a qual a comparamos e cuja fonte, por motivos éticos, não citaremos.

Shemá

Voi che vivete sicuri

Nelle vostre tiepide case,

$V$ oi che trovate tornando a sera

Il cibo caldo e visi amici:

Considerate se questo è un nomo

Che lavora nel fango

Che non conosce pace

Che lotta per mezzo pane

Che muore per un si o per un no.

Considerate s questa è una donna,
Shemá

Vós que viveis seguros

Em vossas casas aquecidas

$V$ ós que encontrais, retornando para casa

Comida quente e rostos amigos:

Considerais se este é um homem

Que trabalha na lama 
Senza capelli e senza nome

Senza più forza di ricordare

$\checkmark$ uoti gli occhi e freddo il grembo

Come una rana d'inverno.

Meditate che questo è stato:

$V i$ comando queste parole.

Scolpitele nel vostro cuore

Stando in casa andando per via,

Coricandovi alzandovi;

Ripetetele ai vostri figli.

O vi si sfaccia la casa,

La malattia vi impedisca,

I vostri nati torcano il viso da voi.

Primo Levi
Que não conbece a paz.

Que luta por meio pão

Que morre por um sim ou por um não.

Considerais se esta é uma mulher

Sem cabelos e sem nome

Sem mais força para recordar

$V$ azios os olhos e frias suas entranhas

Como uma rã no inverno

Meditai que isto aconteceu

Comando-vos estas palavras

Esculpi-as em vosso coração

Estando em casa, andando pela rua

Ao deitar-vos e ao levantar-vos;

Repeti-as aos vossos filhos.

Ou que se desmorone a vossa casa,

Que a doença vós entreva,

Que os vossos filhos vos virem a cara

Primo Levi

Vocês que vivem seguros/Em suas casas/Vocês que voltando à noite/Encontram comida quente e rostos amigos/Pensem bem se se isto é um homem/que trabalha no meio de barro/que não conbece (a) paz/que morre por um sim ou por um não/Pensem se isto é uma mulher/Sem cabelos e sem nome/Sem mais força para lembrar/vazios os olhos, frio o ventre/como um sapo no inverno/Meditai que isto aconteceu./ Recomendo-vos estas palavras,/Gravem-as no vosso coração/estando em casa, andando pela rua, / Ao deitar-vos e ao levantar-vos;/Repeti-as aos vossos filhos./Ou, senão, desmorone-se a sua casa,/Que a doença os torne inválidos, / que seus filhos virem o rosto para não vê-los.

Ao se propor a escrever seu poema, um poeta não sabe ainda quais palavras usará para transmitir seus sentimentos, e escolhe palavras (ou é por elas escolhido) que reproduzem sua subjetividade. $O$ tradutor, então, para recompor o poema de forma semelhante à do poeta, deve "desmontar" os elementos contidos na poesia, procurando significados na língua de chegada os quais, entretanto, nem sempre traduzem o sentimento do poeta. Até então o tradutor era leitor e crítico, porque a leitura é uma tradução e a crítica, ao menos inicialmente, é uma interpretação. É este o momento mais difícil para o tradutor de poesia, porque se o poeta segue as formas tradicionais do fazer poético, ele deverá escolher entre manter a forma original escolhida pelo autor, em detrimento das palavras usadas na tradução, ou manter o significado das palavras traduzidas. Geralmente prefere-se seguir a primeira opção, 
principalmente quando a poesia é de versos livres e, então, não estaria presa à forma poética tradicional de outros momentos literários.

Octávio Paz, ao falar sobre tradução de poesia, afirma que a pior condenação para o ato tradutório cai sobre esta, pois, em teoria, somente os poetas deveriam traduzir poesia, mas na prática, poucas são as vezes em que um poeta é também um bom tradutor. Em outro momento, Paz dirá que tradução e a criação são operações gêmeas e que, se por um lado muitas vezes não é possível diferenciar a tradução da criação, por outro há, entre as duas, um refluxo incessante, de continua e mutua fecundação.

A ideia de texto de Paz aproxima-se da visão que tem Derrida do texto "impuro":

Todo texto é único e, ao mesmo tempo, é a tradução de outro texto. Nenhum texto é completamente original, pois a mesma linguagem, em sua essência, é já uma tradução [...] porque todo signo e toda frase são a tradução de outro signo e de outra frase (tradução nossa). ${ }^{6}$

Também Lawrence Venuti diz que é através da transformação que se chega ao conceito de pluralidade diferencial:

\begin{abstract}
E assim, através da transformação, chegamos ao conceito de diferença, ou differance: enquanto o "original" é diferente de si mesmo, a tradução é diferente do "original". Nem o original, o texto estrangeiro - como Derrida o define em outros lugares - nem a tradução são uma novidade semântica original: os dois são derivantes heterogêneos e contêm vários elementos linguísticos e culturais que desestabilizam a significação, tornando o sentido pluralista e diferencial. Deste modo, seja o original seja a tradução estão em dívida um para com o outro. A tradução, definitivamente não nos coloca em contato com um sentido original (que não existe), mas com a pluralidade diferencial das línguas e dos significados. A ideia da pluralidade diferencial de todo o texto re-define a noção de equivalência da tradução, tornando impossível uma simples correspondência de sentido e situando a tradução em uma relação equívoca assintótica com o texto estrangeiro (tradução nossa) ${ }^{7}$
\end{abstract}

Segundo De Man, a tradução partilha uma característica comum com a crítica, a teoria literária, a filosofia e a história, por serem todas derivações de um

\footnotetext{
${ }^{6}$ DERRIDA, Jacques. Introduzione di Teorie Contemporanee della traduzione, a cura di Siri Nergaard (1998), p. a cura di Siri Nergaard, Milano: Strumenti Bompiani, 1998, p. 47-48.

${ }^{7}$ VENUTI, Lawrence. Rethinking Translation. Discourse, Subjectivity, Ideology. London-New York. Routledeg, 1992, p. 6. In: Teorie Contemporanee della traduzione, a cura di Siri Nergaard, Milano: Strumenti Bompiani, 1998.
} 
original, sendo então leituras, interpretações. A dependência do original (seja ele um texto literário ou um fato histórico), ao desarticulá-lo por meio de sua articulação na linguagem, não prova a superioridade deste, revelando que essa desarticulação já era intrínseca ao original. A desarticulação inerente ao texto original, que percebemos apenas ao traduzirmos, corresponde a uma espécie de alienação - que mantemos inconscientemente, e que advém de nossa própria língua, língua essa na qual nos sentimos à vontade, protegidos, até o momento em que surgem os questionamentos e dúvidas no decorrer do ato tradutório, que Benjamin chama 'aquela maturação póstuma da palavra estrangeira e as contrações da própria'.

Walter Benjamim, em sua obra $A$ tarefa do tradutor, expõe também a sua opinião sobre a originalidade de um texto:

\footnotetext{
A verdadeira tradução é transparente, não encobre o original, não o tira da luz; ela faz com que a pura língua, como que fortalecida por seu próprio meio, recaia ainda mais inteiramente sobre o original. Este efeito é obtido, sobretudo, por uma literalidade na transposição da sintaxe, sendo ela que justamente demonstra ser a palavra - e não a frase - o elemento originário do tradutor. Pois a frase constitui o muro que se ergue da língua original à literalidade, sua arcada. ${ }^{8}$
}

Estas palavras se referem ao fato de que nenhum texto é completamente original porque, a própria linguagem, em sua essência, já é uma tradução, primeiramente do mundo não-verbal, e depois porque cada signo e cada frase são a tradução de outro signo e de outra frase. Tudo isso pode ser invertido, pois todos os textos são originais porque cada tradução é diferente de outra, e na maioria das vezes cada tradução é uma criação e constitui, então, um texto único.

Para Benjamin, a tarefa do tradutor é a de evidenciar a traduzibilidade das obras sem deixar de recordar a complementaridade de cada língua, fazendo com que seus falantes completem a própria língua, excedendo seus

\footnotetext{
8 Apude LAGES, Susana K. In: Walter Benjamim. Tradução \& Melancolia. Paul De Man. "Conclusões 'A Tarefa do Tradutor' de Walter Benjamim, São Paulo: Edusp, 2002, p. 171.
} 
limites, ou então aceitando as digressões propostas por outras, que são atos necessários para a vida da mesma língua.

O filósofo francês Jacques Derrida, em seu ensaio Des Tours de Babel, parte do ensaio de Benjamin, para dar sua interpretação do mito bíblico de Babel, ou seja, do próprio mito da origem da linguagem, relacionando-o ao ato fundamental da nomeação.

Havendo, pois, o Senhor Deus, formado da terra todos os animais do campo, e todas as aves dos céus, trouxe-os ao homem, para ver como este lhes chamaria; e o nome que o homem desse a todos os seres viventes, esse seria o nome deles. ${ }^{9}$

Os ensaios de Paul De $\operatorname{Man}^{10}$ e Jacques Derrida ${ }^{11}$ sobre a tarefa do tradutor converteram o texto de Benjamin numa referência obrigatória para a reflexão do ato tradutório com relação à modernidade e à pós-modernidade, questionando quais seriam as consequências teóricas de uma reflexão - que vê na tradução um momento paradigmático - sobre a natureza da linguagem, assim como sobre seus limites e finalidades, articulando isto com uma discussão da relação entre filosofia e literatura.

Para que possamos nos deter mais especificamente sobre os estudos do ato tradutório, consideramos necessário falar, mesmo que brevemente, sobre línguas e culturas.

O que se entende como língua de um povo não é somente um conjunto de palavras e frases e sim um todo orgânico que se articula, helicoidalmente, com sua cultura. Dentro de cada língua existem variedades e heterogeneidades linguísticas, fazendo com que surjam diferenças entre elas. Nesse sentido, as línguas que nos servem para comunicar, podem nos fechar em uma rede indivisível de sons e de significados, tornando-nos prisioneiros, de forma que cada falante, dentro do próprio "eu”, se sinta só.

\footnotetext{
${ }^{9}$ Genesis, 2, 19

${ }^{10}$ Idem LAGES, p. 171.

${ }^{11}$ Apude DERRIDA, Jacques. In Torres de Babel. Trad. Junia Barreto. Belo Horizonte: Editora UFMG, 2002.
} 
“Aprender a falar significa aprender a traduzir...": assim se inicia o artigo de Octavio Paz, Tradução: literatura e literalidade ${ }^{12}$, porque quando uma criança pede à mãe o significado de uma palavra, na realidade está lhe pedindo para que esta traduza a tal palavra em sua linguagem, demonstrando-nos como numa mesma língua existem situações em que a tradução é necessária para que as pessoas possam se entender.

A mesma coisa acontece em países cujos habitantes falam vários dialetos, verdadeiras línguas, diferentes da língua oficial do país, como é o caso da Itália. E podemos ainda citar os deficientes auditivos cujas palavras "faladas" e "ouvidas" lhes são ditadas pelos sinais.

Isto pode ser confirmado pelas palavras de Octavio Paz quando diz que

[...] a linguagem perde a sua universalidade e se revela como uma pluralidade de línguas, todas estranhas e ininteligíveis entre elas. No passado a tradução dissipava a duvida: se não existe uma língua universal, as línguas formam uma sociedade universal em que todos, superadas certas dificuldades, se entendem e se compreendem. E se compreendem porque mesmo em línguas diferentes, os homens dizem sempre as mesmas coisas. (tradução nossa). ${ }^{13}$

As línguas são sistemas complexos que contêm um conjunto de microsistemas, cujos sentidos - fortemente inspirados nas teorias dos sistemas dinâmicos não-lineares, que vão dos estudos teóricos aos antropológicos, da física às ciências cognitivas, às ciências computacionais, entre outros - são capazes de gerar e fazer emergir significações, seja autonomamente seja nas redes de relações que instauram nos textos, e dentro de cada língua se (re)produzam as divisões: épocas históricas, classes sociais e gerações.

Sendo um texto ou discurso a encarnação da língua, o transportar informações de uma língua para outra significa realizar uma transposição da matéria viva, que é a língua de partida e que deve continuar viva até o final da transposição para a língua de chegada.

12 PAZ, Octávio. Traduzione: letteratura e letterietà. In: Teorie Contemporanee della traduzione, a cura di Siri Nergaard, Milano: Strumenti Bompiani, 1998, p. 284-287. Título original Traducciòn: literatura y literalidad (1970), Barcelona, Tusquets. In Sigma, 1972, p. 33-34.

${ }^{13}$ Idem, pg. 290 
Transpor significados de um espaço para outro, isto é, transpassar palavras de uma língua para outra, significa traduzir e traduzir significa transferir a realidade linguística e cultural da língua de partida para a língua de chegada, até quando esta não corre paralela com a língua original.

E, mais uma vez, para exemplificarmos nossas palavras, falaremos brevemente a respeito da tradução, feita com alunos, de um pequeno livro de contos, Ritratti d'autore - Personaggi e tradizioni del passato ${ }^{14}$, do qual o próprio autor, ao introduzi-los, diz estar falando de personagens e histórias distantes da realidade atual, mas que falam de heranças culturais sicilianas, que se renovam a cada nova leitura a cada nova escritura: pessoas comuns, muitas vezes humildes, que transitavam pelas ruas de pequenas cidades da Sicília.

O trabalho foi muito proveitoso e interessante devido à transposição cultural que a tradução comportava pois, ao traduzir aqueles fatos, colocamos lado a lado duas culturas com suas especificidades, com um imaginário e um 'espírito' próprio. O grande desafio foi a tradução de termos ou de pequenas frases ditas pelas personagens em dialeto siciliano que se tornou possível somente pelas notas do autor e pela origem siciliana do professor.

Reportamos duas falas, em dialeto siciliano, cuja compreensão exigiu que antes fossem traduzidas para a língua italiana e só depois para a portuguesa:

- O salaru, u salaruuu... passa! ${ }^{15}$ (Il venditore, il venditore di sale... passa!)

- O vendedor de sal, o vendedor de sal está passando!

A mula do vendedor de sal era tão inchada e gorda que parecia sempre prenha, e é àquela mula que se deve o antigo ditado siciliano:

- Si chiù grossa da scecca do salaru. ${ }^{16}$ (Sei piú grassa della mula del venditore di sale!), que em português fica: Você é mais gorda do que a mula do vendedor de sal.

\footnotetext{
${ }^{14}$ CHISARI, Mimmo. Ritratti d'autore. Personal Editor. Catania (It.) 1996.

15 Idem, p. 8

${ }^{16}$ Idem, p. 8
} 
Várias vezes, para que obtivéssemos uma boa tradução, foi preciso colocar notas paralelas, como quando para a palavra italiana pale usamos, por aproximação, "folhas" (de figos-da-índia) porque pale traduz a palavra "pás", que não cabe nesse contexto.

E queremos aqui falar um pouco a respeito da tradução de títulos para os quais pode surgir a necessidade de mudança completa. É este o caso de um dos mais famosos romances do renomado autor italiano Alberto Moravia, La ciociara, cujo título precisou ser trocado, porque a Ciociara é o apelido de uma mulher nascida e criada na Ciociaria, região não muito longe de Roma, assim chamada porque seus habitantes, ainda até certa época do século passado, usavam um tipo de calçado formado por uma base cujas amarras vinham se cruzando e subindo até ao joelho, chamadas ciocie. Preferiu-se, então, intitulálo As duas mulheres, pois o romance conta as peripécias da Ciociara e de sua filha.

Ainda na tradução deste romance ocorreu uma coisa bastante estranha: ao "reescrever" o livro, o tradutor deixou de traduzir, para a edição do Brasil, detalhes essenciais, tirando muito do estilo de Moravia, quebrando, às vezes, o impacto causado pela sua narrativa real, quando "deixou passar" toda a descrição minuciosa do não-estupro da experiente Cesira, e do estupro da ainda muito jovem e ingênua filha Rosetta, que Moravia havia descrito de forma muito marcante pelo fato de ela ser ainda virgem e pelo estupro ter sido praticado por um grupo inteiro de soldados estrangeiros. E tudo isso, dentro de uma igreja, bem debaixo do altar.

Perguntamo-nos qual foi o critério que levou o tradutor a reduzir dezenove linhas a apenas três, e a única resposta que podemos nos dar é que, talvez, ele tenha achado esta parte do texto muito real - de um realismo que se aproxima ao obsceno, característica marcante de Moravia - ou que ele possa ter sido influenciado por razões ideológicas, religiosas, ou morais, não 
esquecendo-nos que em 1973 - ano da tradução - no Brasil havia ainda muita censura.

Esta é a tradução, cujo fazer tradutório envolve em primeiro lugar os dois macro-sistemas, Língua e Cultura do texto de partida e do texto de chegada, dentro dos quais se inscreve um conjunto de mundos de múltiplas facetas: o mundo do Autor e o mundo do Tradutor, estritamente independentes e separáveis somente por finalidades analíticas.

A respeito disso, podemos citar Jiri Levý o qual diz que

\begin{abstract}
(...) a tradução é um processo de comunicação: o objetivo de traduzir é o de comunicar o sentido do original ao leitor estrangeiro. Do ponto de vista prático do tradutor, em cada momento de seu trabalho (isto é, do ponto de vista pragmático) a atividade de traduzir é um processo de decisão: uma série de situações consecutivas - de movimentos, como em um jogo -, situações que impõem ao tradutor a necessidade de escolher entre um número de alternativas. ${ }^{17}$
\end{abstract}

Traduzir ajuda também a conhecer com maior profundidade as ideias e estilos dos autores traduzidos e perceber que há entre eles pontos de convergência e de divergência. $O$ tradutor precisa, então, estar convencido de sua veracidade, pois ao endossar um original apócrifo, arriscaria sua reputação, porque estaria assinando com o autor e emprestando a este sua reputação para o novo texto, resultado de sua tradução.

O que expomos até então são pontos de vista de alguns pesquisadores da tradução que respondem a perguntas sobre o ato tradutório em si. Mas desde quando existe a tradução? E desde quando existem estudos concretos sobre o ato tradutório?

A atividade de traduzir existe desde as chamadas línguas "pósbabélicas", e se traduz sempre mais, porque traduzir suprime as diferenças entre uma língua e outra, revelando-as mais evidentes, assim que, graças à tradução, sabemos o que os outros povos pensam, dizem e fazem, e isso muitas vezes pode ser um estímulo para inovar e até mesmo para corrigir algo

${ }^{17}$ LEVÝ, Jiri. La traduzione come processo decisionale. In Teorie Contemporanee della traduzione, (a cura di) Siri Nergaard, Título original: "Translation as a Decision Process" (1967). In: To Honor Roman Jakobson: Essayes on the Occasion of his Seventh Birthday, 11 October 1966, vol. 3, The Mouton, Hauge, 1967, II, p. 1171-1182. 
de nossa própria língua que não havíamos percebido e cujas diferenças, desde o inicio do último século, vêm sendo objeto de estudos de filósofos, historiadores, antropólogos e linguistas.

A documentação que demonstra a existência da tradução remonta há muitos séculos e a encontramos em memórias escritas, em todas as partes do mundo onde havia culturas que registraram e acompanharam os momentos originários e relevantes da vida de todas as grandes línguas de que temos memória, até mesmo do homem da pré-história, o qual registrava o seu cotidiano através de imagens pictóricas nas cavernas, hoje objeto de análise arqueológica, antropológica e de outras ciências, entre as quais a tradutologia. Alguns milênios de história fazem da tradução um patrimônio cultural de valor inestimável.

Para as culturas do Velho Mundo - ao qual pertence à Itália - traduzir era uma atividade habitual dos grandes escritores, que, mesmo antes de escreverem suas obras, haviam traduzido os clássicos, ou seja, os cânones das literaturas grega e latina. Tais traduções espelhavam o recalque tradutório do grego. Posteriormente, as antigas línguas da Europa foram consolidadas através das traduções de textos latinos da época clássica e da cristã, e foram enriquecidas por uma grande influência vocabular das línguas dos "povos bárbaros".

No Brasil, país do Novo Mundo, a tradução foi condição fundamental para o seu desenvolvimento cultural, pois a princípio tudo era necessariamente traduzido, e, devido à confluência de várias culturas, foram necessárias várias traduções das línguas introduzidas pelos que aqui se aventuraram, para que obras literárias, e não-literárias, assim como documentos necessários à vida política do país, fossem lidas. Atualmente, a literatura brasileira é traduzida na Europa e em outros países, que reconhecem o valor literário de seus autores e de suas obras. 
Atualmente, qualquer leitor, em qualquer parte do mundo - devido à universalidade da tradução, pode encontrar obras literárias famosas que the propiciam o prazer da leitura de autores até então desconhecidos ou conhecidos apenas pela fama internacional.

Tomamos como ponto de partida os estudos já realizados para observarmos as teorias estabelecidas, que ultrapassam as fronteiras das culturas e que se tornam cada vez mais ricas quando acrescidas de suas informações peculiares, completando as estruturas das línguas utilizadas.

Os estudos da tradutologia como ciência são relativamente novos, e até hoje não existe uma história da tradução completa e abrangente. Uma das causas desta lacuna teórica pode estar no fato de que a tradução sempre sofreu, e até hoje ainda sofre, por ter um papel marginalizado e subordinado diante dos outros tipos de (re)escritura. E o fato da tradução ser uma (re)escritura faz pensar que é, ou deveria ser, um texto que reproduz de forma idêntica o texto original em outra(s) língua(s), e este (re)produzir faz com que se pense não ser a tradução arte tanto quanto a literatura, a pintura etc.

Muitos são os ensaios de autores que se dedicaram, e se dedicam, aos estudos da tradução, envolvendo-se com a sua classificação, seu fazer histórico, linguístico, filosófico e semiótico, que faziam, e que fazem, suas colocações, posicionamentos e debates em prol da tradutologia e contribuíram para que hoje se tenha formado, de forma mais incisiva, um campo bastante amplo e produtivo. Porém, somente após a segunda guerra mundial, se perceberam os primeiros sinais que indicavam a necessidade de estudos referentes aos problemas inerentes à tradução, desenvolvidos com critérios metodológicos rigorosos.

A disciplina que se queria instituir recebeu diversos nomes, cada qual refletindo uma impostação teórica diferente. Para conhecer os vários pontos de vista com que se estudou o ato tradutório, basta percorrer a 
história inicial desses nomes, como, por exemplo, ciência da tradução, teoria da tradução, tradutologia e, por fim, translation studies. ${ }^{18}$

Tais impostações teóricas foram muitas e variavam na definição do objeto disciplinar, na definição do que era uma tradução, no que queira dizer traduzir e na natureza do trabalho de quem traduzia.

Apesar dos conflitos internos e das posições contrastantes que ocorreram ao longo das últimas décadas, assistimos ao emergir de inúmeros estudos sobre tal assunto que, aos poucos e de forma a provocar uma evolução não linear e simples, deram a partida para a formação de uma verdadeira disciplina autônoma.

Para que tais momentos possam ser melhor identificados foram divididos, grosso modo, em primeira, segunda e terceira geração.

- Primeira geração - Para uma Ciência da tradução.

Nos anos cinquenta/sessenta a disciplina que se ocuparia do ato tradutório chamou-se de "ciência", cujo surgimento do interesse se deve às tentativas automáticas de tradução, realizadas através do computador. De fato se pensava que o fenômeno da tradução pudesse ser descrito, esquematizado e formalizado em termos lógicos, e a pesquisa seria impostada a exemplo da lógica das calculadoras, dando um cunho claramente cientifico àquela primeira fase de estudos.

Os linguistas (entre os quais Jakobson), que inicialmente pretendiam resolver o problema da tradução, abandonaram tal prática, continuando a serem influenciados pela matemática da informação. Começava a afirmar-se a abordagem gerativista de Chomsky, cujos trabalhos eram exemplos para os primeiros "cientistas" e para a formação da teoria da Ciência da tradução, até mesmo para os estudos não diretamente ligados à tradução.

Mais uma vez nos reportamos a Otavio Paz, quando diz que:

${ }^{18}$ HOLMES, James S. The Name and Nature of Translation Studies (1972), in Holmes, 1988, p. 67-91 
Não há, nem pode haver uma ciência da tradução, mesmo que esta deva e possa ser estudada cientificamente, pois, assim como a literatura é uma função especializada da linguagem, a tradução é uma função especializada da literatura (tradução nossa). ${ }^{19}$

Em breve tempo se teve, nesse período

[...] um geral cientificismo da língua e do ato linguístico que, no que concerne à tradução, contribui, porém, a subavaliar a influencia que esta atividade particular pode ter sobre a língua, sobre os processos de comunicação e da cultura. ${ }^{20}$

A tradução era feita em nível da palavra ou, no máximo, da frase, fazendo-se, então, uma transposição quase somente terminológica, e os textos utilizados eram prevalentemente não literários. As teorias, altamente formalizadas, deviam ter uma função prática, porque deviam servir como instruções e regras para o tradutor, tomando, então, um viés muito normativo. Tal abordagem científica e prescritiva, em breve tempo, se mostrou inadequada para tratar do fenômeno da tradução, e uma das principais razões foi que

[...] enquanto a linguística - devido à sua impostação estruturalista indaga a natureza e a estrutura da língua (no sentido da langue saussuriana), a tradução não se refere a uma transposição de língua para língua, mas de texto para texto. Trata-se, então, de uma relação que se situa a nível da parole. ${ }^{21}$

A linguística de então se ocupava da língua como um sistema e de seu aspecto sincrônico, enquanto a tradução era um fato dinâmico que acontecia na diacronia. Ainda nos dias de hoje a linguística se ocupa dos textos e dos discursos (sociolinguística e psicolinguística), mas, apesar desta evolução, uma abordagem meramente linguística tem demonstrado ser pouco útil para uma teoria da tradução.

\footnotetext{
19 PAZ,Octavio. Traduzione: letteratura e letteralità. In Teorie Contemporanee della traduzione, a cura di Siri Nergaard (1998), p. 290.

${ }^{20}$ NERGAARD, Siri (a cura di). Teorie contempoarnee della tradurione. Milano: Bompiani, 1995, p. 20.

${ }^{21}$ Idem, p. 8.
} 
O teórico Antony Pym (1992, p.186) ${ }^{22}$ diz que tal abordagem, mais do que demonstrar limites linguísticos, quer afirmar que a teoria da tradução não constitui um ramo da linguística, embora possa lhe fornecer o que ela em si mesma não consegue abarcar.

\section{- Segunda geração - Para uma Teoria da traducão}

Entre o final dos anos setenta e o início dos oitenta, iniciou-se uma verdadeira reação anti-linguística: por debaixo do rótulo Teoria se faziam as primeiras tentativas de fundar uma disciplina que não fosse nem científica nem prescritiva, mas que privilegiasse os textos literários até então excluídos, provocando uma virada radical. Tudo isso baseado em critérios de cientificidade que preferiam falar de teoria, ou melhor, de teorias da tradução que tivessem a função de compreender o fenômeno em si porque nascidas do estudo deste. Pretendia-se não mais fazer da tradução uma série de regras e ambivalências, mas a descrição dos "fatores que fazem de uma tradução a tradução": essa teoria, chamada por Berman de tradutologia, era "uma reflexão que a tradução fazia sobre si mesma, a partir do fato de ser ela uma experiência" $\left(1985\right.$, p.39) ${ }^{23}$.

Sua evolução corre paralela à evolução das teorias do texto, estimulada seja pela linguística textual, seja pelas teorias do texto em geral. No campo da tradução acontece um deslocamento gradual de interesse das chamadas relações interlinguísticas para as intertextuais. Vale aqui dizer que os maiores estudos para a evolução de uma teoria da tradução do texto literário se devem aos formalistas russos (Jakobson, Levý, Lotman, etc.).

Terceira Geração: Para uma disciplina chamada Translation Studeis. ${ }^{24}$

22 PYM, Antony. Translation and Text tranfer. An Essay on the Principles of Intercultural Communication, Frankfurt am Main-Berlim-New York-Paris-Wien, Peter Lang. 1992, p. 186, In: Teorie contemporanne della traduzione, a cura di NERGAARD. Milano: Bompiani, 1995.

${ }^{23}$ BERMAN, Antoine Le tours de Babel: Essais su La traductión. Mauvezin, Trans-Europ-Repress, 1985.

${ }^{24}$ NERGAARD, Siri (a cura di). Teorie contemporanee della traduæione. Milano: Bompiani, 1995, nota p. 13. "No artigo The nome and Nature of Tanslation Studies, de 1972, Holmes propõe chamar os estudos de Translation Sudies para definir uma disciplina empírica cujos principais objetivos são (1) 'descrever o fenômeno do traduzir e da tradução como se manifestam no mundo de nossa experiência e 2) estabelecer principais gerais por meio dos 
Sob esta definição são resumidos vários percursos de pesquisas feitas por teóricos de várias nacionalidades, acomunados pela centralidade atribuída ao texto de chegada. Agora a tradução não é mais tratada em relação ao texto de partida, mas é analisada em sua essência de obra pertencente a um preciso texto sociocultural. Para os estudiosos da Translation Studies o objetivo primário não era de formular uma teoria da tradução, mas de estudar o processo tradutório.

O crescimento da Translation Studies como disciplina especifica é a história de um grande sucesso dos anos 80, confirmada pelo proliferar de estudos e pesquisas desta década e mais ainda pelo nascimento de cursos universitários em Teoria da tradução ou em Translation studies, além de publicações e estudos, de conferências e seminários.

Segundo Pym (1992, p.183) este nome define a disciplina de tradução, que deveria assim ser chamada porque não era uma ciência, nem, talvez, uma teoria - não porque nenhuma das teorias fosse correta, mas porque eram poucos os critérios, geralmente reconhecidos, com os quais se pudesse demonstrar que uma teoria estivesse errada - mas era um campo de estudos interdisciplinares, e não tinha modelos e/ou instruções que mostrassem como traduzir. Esta opinião foi defendida por muitos estudiosos, enquanto outros tentavam transformá-la em ciência através da linguística, e outros ainda pensavam em estudá-la como linguística científica. E não era uma teoria, pois esta requereria maior uniformidade e univocidade de quanto se pudesse extrair dos estudos de tradução, e a teoria não deveria propor regras para os tradutores, pois "uma teoria útil deveria ter como base uma prática autônoma na resolução de seus problemas" ${ }^{25}$.

quais estes fenômenos podem ser explicados e previstos' (1988, p 71). Holmes define a primeira das duas de descreptive translation studies (estudos de tradução descritivos), a segunda de theoretical translation studies (estudos de tradução teóricos)"

25 PYM, Antony. In: Teorie contemporanee della traduzione, a cura di Siri Nergraard, Milano: Bompiani, 1995, p. 14 
A afirmação que a tradução refere-se à cultura mais do que à língua de um país nasce do fato que, entre todas as dificuldades e aspectos que devem ser levados em consideração, "a linguagem é talvez a menos importante" (Nergaard, 1995, p.15). Essas palavras não estão dizendo nada de novo, pois já Nida havia dito que "as diferenças entre as culturas podem causar, ao tradutor, mais problemas do que as diferenças entre as estruturas linguísticas" (Nergaard, 1995, p.15).

E aqui gostaríamos, mais uma vez, de exemplificar com uma realidade comum da cultura siciliana, onde quem trazia presentes às crianças não era $\mathrm{o}$ agora famoso Babbo Natale e nem a também famosa Befana (uma velha bruxa que voava no cabo de uma vassoura), mas eram os mortos, e isso era típico da Sicília e não de outras regiões italianas.

Nida também diz que "traduzir consiste em produzir na língua de chegada o equivalente natural mais próximo à mensagem da língua de partida, primeiramente no significado, depois no estilo". Isso resulta do fato que ele atribui um valor principal ao sentido comunicativo, isto é, ao propósito de se criar, em qualquer língua, uma mensagem clara e inteligível, pois é de fundamental importância que um texto seja funcional no contexto em que se traduz e

[...] que não somente a abordagem mais adequada é a de natureza sociolingüística, mas que uma sociolingüística desse gênero deveria depender de uma semiótica antropológica (1967, p. 77). Segundo o autor é, de fato, através de uma visão etnolinguística da comunicação que se podem compreender '(1) perda de informação, (2) acréscimo de informação, e /ou (3) desvio da informação' que todos os tipos de tradução comportam. (NIDA, 1964, p.121).

É certamente por isso que atualmente vários teóricos preferem dizer que traduzir é um ato de comunicação que acontece entre culturas, isto é, que a Translation Studies não é uma disciplina, mas sim um campo de estudos interdisciplinares.

A este respeito Quine diz que: 
Manuais para traduzir de uma língua para outra podem ser compostos de modos divergentes, todos compatíveis com a totalidade das disposições verbais, e mesmo assim incompatíveis entre si (1960, tr. it.: 39). (Exatamente nesta afirmação encontra-se seu princípio de "indeterminação da tradução")

Mudaria, porém, o modo de se observarem tais conceitos e o paradigma dentro do qual eram examinados. Em vários contextos, considerados por alguns dos maiores inovadores de tradutologia (Hatim and Mason, 1990; Bassnett and Lefevere, 1991; Pym, 1992), se preferia falar da tradução como comunicação intercultural. E dentro do conceito de Translation Studies, ocorreu também o do Cultural turn, o qual preconizava que a unidade de análise se deslocasse do texto para a cultura, fazendo com que se definisse o ato tradutório como um ato de comunicação entre culturas.

Também Jakobson ${ }^{26}$ havia dito que "as línguas se diferem entre si essencialmente por aquilo que devem expressar, não por aquilo que podem expressar".

Henri Meschonnic, para definir a tradução, antecipa a target-oriented, isto é, a perspectiva que coloca em primeiro lugar seja o contexto cultural-literário de chegada, seja a integração do aspecto natural e histórico:

A força e a fraqueza da tradução, na literatura de chegada, num certo momento, delimitam até mesmo o possível de traduzir. Tal possível não se define então no confronto abstrato do texto de partida com a sua tradução, mas na unidade cultura-lingua-tempo. ${ }^{27}$

No final dos anos noventa ainda não se havia chegado a nenhuma conclusão a respeito da evolução das teorias ocorridas no decorrer da década, mas certamente o papel central era o dos estudos de impostação pósestruturalista, os quais, por sua vez, foram influenciados por alguns escritores desconstrucionistas.

\footnotetext{
${ }^{26}$ JAKOBSON, Roman. Aspetti linguistici della traduzione. In: Teorie contemporanee della traduzione, (a cura) di Siri Nergaard. Milano: I edizione Strumenti Bompiani, 1995, p. 59.

27 MESCHONNIC, Henri. Proposizioni per una poetica della traduzione. In: Teorie contemporanee della traduzione, (a cura) di Siri Nergaard. Milano: I edizione Strumenti Bompiani, 1995, p. 186 e 187.
} 
Gedeon Toury, um dos mais importantes expoentes da corrente chamada de Target-oriented, diz que "os tradutores operam primeiramente e principalmente no interesse da cultura para a qual estão traduzindo, e não certamente em razão do texto de partida, colocando assim de fato entre parêntesis a cultura que o originou" (Toury, 1995, p.36)

A disciplina descritiva, da qual Toury quer fundar as bases, nasce como proposta alternativa à abordagem normativa e apriorística, (source-oriented), isto é, que parte dos originais para individualizar os eventuais problemas de tradução e estabelecer como devem ser resolvidos. Esta nova abordagem parte das próprias traduções e tem a finalidade de individualizar e reconstruir as estratégias, as normas e os vínculos que decidiram a conformação da tradução.

Tudo isso

[...] Porque uma tradução nunca consiste em uma operação neutra e independente, mas numa serie de condicionamentos mais ou menos fortes que dependem do sistema de chegada, e são estes que determinam restrições e vínculos. E é também estabelecida, a posteriori, a definição de uma tradução, pois são traduções aqueles textos que são considerados tais "do ponto de vista da própria cultura de chegada, sem fazer nenhuma referência aos seus supostos correspondentes textos de partida, ou melhor, sem levar em conta a própria possibilidade da existência dos textos. [...] Sempre de um ponto de vista do sistema de chegada, a literatura traduzida constitui um sistema literário particular, o qual joga intersistemicamente e intertextualmente com outros sistemas. [...] $\mathrm{O}$ fato que torna esta visão muito interessante para o nosso discurso é, ao invés, o de demonstrar quanto as traduções singulares sejam influenciadas e condicionadas pelas outras traduções efetuadas na mesma cultura, e pelo sistema literário geral desta cultura. ${ }^{28}$

Também George Steiner, em seu livro Após Babel, fala da tradução como de um processo que acontece não tão somente na transposição de uma língua para outra, mas em todo o ato de leitura, isto é, em sua interpretação: "Leitor, ator e curador são tradutores de uma linguagem fora de seu tempo" (1975, tr. it.: 28, cit. Nergaard, 1995, p.38).

\footnotetext{
${ }^{28}$ NERGAARD, Siri (a cura di) Teorie contemporanee della traduzione, (a cura), I ed. Strumenti Bompiani, 1995, pg. 36 e 37, citando Toury In: Principi per un'analisi descrittiva della tradurione, p. 181-223.
} 
Nunca como na última década do século passado, e no inicio deste, se falou tanto em tradução como comunicação intercultural e como elo entre as várias e diversas perspectivas como a multicultural, a multi-étnica e a póscolonial.

Estudar a tradução no sentido pós-estruturalista significava, por exemplo, pesquisar a tradução entre culturas dominantes e culturas dominadas (Jacquemond, 1992), tradução e colonialismo (Sengupta, 1991), tradução e ideologia (Lefevere, 1992) e tradução e subjetividade (Venuti, 1992).

Segundo Georges Mounin (2006, p.22) a Tradução moderna engloba a tradução Interlinear, a Literal e a Moderna propriamente dita, e

[...] é o resultado de toda a experiência do passado, neste campo: ela procura respeitar - quando possível - a língua estrangeira em cada palavra, em cada construção e em todas as suas formas estilísticas. Mas se preocupa também em não violar nunca a língua na qual transpõe o original, respeitando, então, contemporaneamente o espírito da língua original e aquele da língua em que se traduz; tudo isso se mantendo sempre fiel ao sentido do texto, sem acrescentar, retirar ou mudar nada. (tradução nossa). ${ }^{29}$

Para concluir esse nosso trabalho, lançamos mão das palavras que Umberto Eco escreve em sua obra Dire quasi la stessa cosa:

Di qui nasce l'idea che la traduzione si fondi su alcuni processi di negoziazione essendo la negoziazione appunto um processo in base al quale per ottenere qualcosa, si rinuncia a qualcosa d'altro - e alle fine le parti in gioco dovrebbero uscire con un senso di ragionevole e reciproca soddisfazione alla luce dell'aureo principio che non si può avere tutto 30

Novas terras, novas culturas e novos esforços aparecem no horizonte que restitui uma paisagem ainda mais fascinante, um terreno mais fértil para o cultivo - apesar da Torre de Babel - das diferenças e das complexidades, para cooperar, compartilhar e negociar, através da língua, a linguagem da cultura e

\footnotetext{
${ }^{29}$ MOUNIN, Georges. Teoria e storia della traduzione, Traductions et Traduceurs em francês e traduzida para o italiano por Stefania Morganti. Torino: Giulio Einaudi editore s.p.a., 1965 e 2006.

${ }^{30}$ ECO, Umberto. Dire quasi la stessa cosa. Milano: Collana Studi Bompiani, 2003. "Disso nasce a ideia que a tradução se fundamenta em alguns processos de negociação, sendo esta exatamente um processo com base no qual para obter alguma coisa, se renuncia a outra coisa - e, no final as partes em jogo deveriam sair com um sentido de legitima e recíproca satisfação à luz do áureo principio que não se pode ter tudo" 30
} 
as outras linguagens, com os atores dos diálogos, a sua vez, ouvintes, tradutores ou vice-versa, para que possam prosseguir sua viagem.

\section{REFERÊNCIAS BIBLIOGRÁFICAS}

AUBERT, Francis Henrik - As (In)Fidelidades da Tradução: Servidões e autonomia do tradutor. Campinas, SP: Editora da UNICAMP, 1994.

ARROJO, Rosemary. Oficina de tradução, 3ª ed. São Paulo: Ática,1997. - (org). O signo descontraído - implicações para a tradução, a leitura e o ensino. Campinas: Ponte, 1992.

BARBOSA, Heloisa Gonçalves - Procedimentos Técnicos da Tradução: una nova proposta - Campinas, SP: Pontes, 1990.

BERMAN, Antoine, A prova do estrangeiro. São Paulo: EDUSC.

CAMPOS. Haroldo de. "Paul Valery e a poética da tradução", in Limites da traduribilidade. Salvador: EDUFBA, 1966.

CATFORD, J.C. Uma teoria lingüistica da tradução. SP: Edit Cultrix \& PUC/Campinas, 1980.

CÉSAR, Ana Cristina."Bastidores da tradução", in Escritos da Inglaterra. São Paulo: Brasiliense, 1988.

DERRIDA, Jacques. Des Tours de Babel. Trad. de Junia Barreto, Belo Horizonte: Editora UFMG, 2002.

Devoto, G. e G.C. OLI. - Dizionario della Lingua Italiana. Firenze: Le Monnier, Settima ristampa: luglio 1976.

ECO, Umberto. Riflessioni teórico-pratiche sulla traduzione. In Teorie contemporanee della tradurione a cura di Siri Nergaard. Milano: I ed Strumenti Bompiani, aprile 1995.

Dire quasi la stessa cosa. Milano: Bompiani, 2003.

FALQUI, E. Prosatori e narratori del Novecento italiano. Torino: 1950. 
LAGES, Susana K. Walter Benjamin. Tradução e melancolia. São Paulo: EDUSP, 2002.

LARANJEIRA, Mário - Poética da traducão: do sentido à significância. EDUSP FAPESP.

MARTINS, Claudia de Rezende \& CORREA, Angela. "Estratégias do processo tradutório". In Estudos de tradutologia, vol.1, Brasília: Kontakt, 1981.

MOUNIN, G. Os Problemas Teóricos da Tradução. Tradução de Heloysa de Lima Dantas de Les problèmes théoriques de la traduction, Paris 1963. São Paulo: Cultrix, 1975.

NERGAARD, Siri (org.), La teoria della tradurione nella storia. Milano: Bompiani, 1993.

1995.

(org.) Teorie contemporanee della tradurione. Milano: Bompiani,

OSIMO, Bruno. Manuale del traduttore - Guida pratico e Glossário. Milano: Editore Ulrico Hoelpi, 1998.

OTTONI, Paulo (org). Tradução: a prática da diferença. Campinas, SP: Editora da UNICAMP, FAPESP, 1998.

PAES, José Paulo. Traducão, a ponte necessária. Aspectos e problemas da arte de traduæiri. São Paulo: Ática, 1990.

RODRIGUES, Cristina Carneiro. Tradução e diferença. São Paulo: Editora UNESP, 2000.

RÓNAI, Paulo. A tradução vivida. Rio de Janeiro: Nova Fronteira, 1981.

Babel e Antibabel. São Paulo: Perspectiva, 1970.

\& alii. A tradução técnica e seus problemas. São Paulo: Álamo,

1984.

SPINELLI, V. e CASASANTA, M. Dizionario completo Italiano Portoghese (Brasiliano) e Portoghese (Brasiliano) - Italiano. Milano: Editore Ulrico Hoelpi S.p.A., 1985. 